\title{
DIGITAL ENGINEERING: COMPETENCE ACQUISITION AND PROGRAM DEVELOPMENT AS AN OPEN CO-CREATION PROCESS
}

\author{
Vanessa Mai, Susanne Wolf, Paul Varney, Martin Bonnet, \& Anja Richert \\ Faculty of Process Engineering, Energy and Mechanical Systems, TH Köln (Germany)
}

\begin{abstract}
Dealing with the increasingly complex interrelationships in companies, technologies and markets requires engineers to have a holistic, systemic understanding of digital change. Future engineers need future skills and must be able to react to ever faster changing technical requirements by independently expanding their knowledge, developing (technology-based) solution strategies as well as designing, evaluating and communicating these with regard to social, ecological and cultural aspects and requirements. In order to integrate these future skills into existing curricula, study programs must be designed in such a way that they are permeable to continuous and agile adaptation in relation to new knowledge and new technologies. This process can only succeed if universities see themselves as open learning systems that promote co-creation processes among all university stakeholders.

The Faculty of Process Engineering, Energy and Mechanical Systems at TH Köln/University of Applied Sciences has recently recognized the resulting need for a transformation process in program development and has further developed the consecutive master's program "Mechanical Engineering/Smart Systems", in which agile learning environments and innovation spaces are created. However, the redesign and further development of modules is not enough. A holistic, systemic understanding in dealing with transformative technologies requires a cultural change in which lecturers and students shape the digital transformation on an equal footing. In a joint learning and research process, they iteratively and agilely test which competencies best prepare students for an increasingly digitalized workplace and which analog and virtual learning spaces this requires.

As part of the project "Digital Engineering - Competence Acquisition for Mechanical Engineers in the Digital Age", the faculty is currently implementing the Technology Area, a measure whose aim is to accompany these digital transformation processes at the faculty and to provide lecturers and students with the necessary freedom to experiment with new technologies in teaching. Here, subject-specific teaching and research concepts for the use of new technologies are to be developed and tested together in a co-creation process. The first concepts developed in the Technology Area as well as other Best Practices from the faculty will be presented in the paper. These include the Mixed-Reality-Game FutureING, the Serious Game Worlds of Materials and the development of a StudiCoachBot. In order to promote co-creation processes within and outside the university, a Digitalization Conference was held in May as part of the project to present innovative and forward-looking innovations in engineering education. The reflection of all of the presented initiatives is structurally anchored and professionalized by the House of Excellence in Engineering Education.
\end{abstract}

Keywords: Engineering education, digital transformation, digital engineering, co-creation processes, program development.

\section{Requirements for an engineering education fit for the future}

Dealing with increasingly complex contexts (companies, technologies, markets) requires engineers to have a holistic understanding of the challenges of digital transformation. They must combine technical and methodological competencies (STEM fundamentals) with specialized technical competencies (e.g., from mechanical engineering, computer science, etc.) and interdisciplinary competencies (VDMA 2019, VDI 2019). These competencies are often still addressed separately in engineering education, so that students specifically experience the acquisition of future skills (Stifterverband 2019a, Stifterverband 2019b) as an add-on rather than an integral part of their studies. Integrative teaching requires innovative formats of physical, virtual, and hybrid teaching and learning, as well as curricular structures that are sufficiently flexible to respond dynamically to changing job profiles. 
The Faculty of Process Engineering, Energy and Mechanical Systems at TH Köln - University of Applied Sciences is responding to these requirements with its project "Digital Engineering Competence Acquisition for Mechanical Engineers in the Digital Age" (TH Köln 2020), the aim of which is to initiate a culture of joint research and creation processes. As part of the project, the master's program "Smart Systems - Sociotechnical Systems" was developed, in which agile learning environments and innovation spaces enable future mechanical engineers to acquire competencies in the digital age (see section 2). In addition to that, a Technology Area is currently being implemented in which subject-specific teaching and research concepts for the use of new technologies are being developed and tested. The following section describes successfully tested and innovative teaching and learning concepts for the acquisition of employability skills that have been developed in the faculty and/or in the Technology Area. Both measures are elements of a transformation process at the faculty, which enables innovative and hybrid teaching and learning settings on a curricular and didactic level to foster the acquisition of employability skills in a co-creation processes between students and lecturers. This transformation process is also professionalized and structurally anchored in the House of Excellence in Engineering Education (HEEE) (see section 4).

\section{Master's program "mechanical engineering/smart systems": Program development as a co-creation process}

The master's program "Mechanical Engineering/Smart Systems" developed at the faculty and accredited in 2020 is characterized by a consistent competence and research orientation. For this purpose, competencies are bundled in competence clusters, which are trained in an integrated manner in experience-based and research-based learning settings. These competencies are thought of integrally and interconnectedly from the very beginning. The program is also closely interlinked with the BA program in mechanical engineering and also ensures the continuous acquisition and development of competencies across the degree programs (TH Köln 2020a).

The study program makes a valuable contribution to the digitalization of teaching and consistently implements so-called seamless learning - understood as learning across different contexts - in a model-building way by integrating analog and digital forms of teaching/learning in the modules by combining presence and AR/VR applications, offering time- and location-independent research and teaching, alternating formal with informal teaching formats, and networking different modules in the BA and MA study programs. Thus, the program makes a transformative contribution to the consistent networking of BA and MA study programs in curriculum development.

A special feature of the program development process presented here are also the initiated exchange and reflection formats in the curriculum workshop of the MA study program. In this bi-weekly format, peer-to-peer coaching and reflection on the modules of the participating professors and lecturers takes place on a regular basis. Within this framework, all courses, their didactic elements as well as their content and curricular integration with those of other colleagues are reflected upon. For the MA study program, it was also possible to recruit lecturers from other research-oriented faculties, thus advancing the interdisciplinary networking of relevant university actors at the curricular level. These initiatives in program development have a model-building effect for the programs of the entire university and especially for the other engineering faculties.

\section{FacING digitalization in the technology area: Contemporary competence acquisition in engineering education}

The Technology Area established at the faculty is a permanent, hybrid space where lecturers and students test new technologies. They can "check in" here with an idea for implementing technologies in teaching and develop subject didactics for using technologies in teaching. In this way, researching and teaching professors and staff, together with students, can bring their (research) expertise into teaching, both in terms of subject-specific methodology (real labs, empirical studies, etc.) and in terms of teaching-learning research (subject-specific didactic research questions). They are given freedom to conduct research, test new teaching/learning fields and the latest technologies. The results serve as teaching impulses in the project- and research-oriented modules. In the premises, demonstrators are made available by the faculty and in cooperation with other engineering faculties of TH Köln - University of Applied Sciences for use in teaching as a kind of "parcours". Currently, the Technology Area exists as a virtual space due to the Covid-19 pandemic. The construction of a container on campus is planned for the end of 2021 in order to also provide a physical space. The Technology Area currently includes a telepresence robot (Double III), a virtualizer, AR/VR glasses (HTC Vive, HoloLens) as well as a 360 Degree Camera and a Merge Cube. 
Innovative teaching concepts are being developed, shared and made visible in cross-faculty exchanges. The first best practices developed at the faculty and/or in the Technology Area are presented below. In addition, as part of the Curriculum 4.0 project, the first three-day "FacING Digitalization" conference was hosted at TH Köln - University of Applied Sciences in May 2021 (TH Köln 2021). Here, innovative and future-oriented technologies in engineering education were presented. In addition to university stakeholders and students, external experts and practitioners were also involved.

\subsection{Mixed-Reality-Game FutureING: AR/VR/MR technologies in engineering education}

Hybrid and digital learning worlds are playing an increasingly important role in education and offer opportunities for open communication, the mapping and support of individual learning processes, as well as networked learning independent of time and place. In the BA study programs Mechanical Engineering, Renewable Energies, Energy and Building Services Engineering, Mobile Work Machines and Rescue Engineering, the first-year compulsory course "Work Techniques and Project Organization" is offered at the faculty for approximately 800 students per year. This course was transformed from a classical lecture with seminar-based elements to a more future-oriented concept by integrating the mixed reality game FutureING in the winter term of 2020/21 (Richert et al. 2019). Using Augmented Reality (AR) and Virtual Reality (VR) technologies and incorporating reflection and feedback-oriented formats, digital learning worlds were created in which students can build subject-specific and interdisciplinary competencies and experiences together and individually as well as test themselves in different roles. FutureING integrates the existing components of the course with an analogous business game into a digital, game-based overall concept. In this way, the mixed reality game succeeds in making reflection-promoting and diversity-oriented formats scalable even for large numbers of participants.

As early as in the first semester of their engineering studies, students thus have the opportunity to experience the digital transformation in a production company. FutureING consists of interconnected game modules. When playing, students form virtual engineering offices, that are given the task of designing and optimizing the production processes of a robotics manufacturer in the AR part of the game. In the VR part, the groups of students enter their planned factories and solve occurring problems during a production cycle. In this process, students are trained to act in a technically sound manner when working on and solving complex problems, as well as communication and teamwork skills and project organization techniques, which are regularly reflected upon. By creating this experiential, immersive and hybrid learning environment, a learning atmosphere is created in which open exchange takes place, thought processes are stimulated and reflection on learning processes takes place.

With the mixed reality game FutureING, the faculty is trying to set new national and international standards in media and university didactics. The accompanying research taking place within this framework focuses on the effects of structural changes on learning success and thus provides a valuable contribution to university didactics. It puts the possibilities of improving teaching through the use of digital media on a solid data basis. For the mixed reality game, on the one hand, in-game data is collected to identify patterns in player behavior, and performance parameters on the required competencies are developed and operationalized. In addition, students' self-assessment of skill acquisition will be investigated concurrently (Varney et al. in press). Serious changes are expected both in the way students learn and work and in the levels of competence they achieve. Linked to this is the further development of examination formats that no longer test classical knowledge but make competencies visible in the sense of performance analyses.

\subsection{StudiCoachBot: Accompanying digital learning processes}

Competency-based teaching/learning settings thrive on systematic and process-oriented feedback so that students can ascertain their learning status and lecturers can steer learning processes. Since reflection and feedback processes are time- and staff-intensive, scaling them for large groups is challenging. Digital media and AI-based technologies can help make feedback more individualized, systematic, and process-oriented. They enable low-threshold, automated feedback and encourage self-coaching processes in preparation for face-to-face reflection sessions.

In this context, AI-based dialogical communication systems are being used increasingly in the context of higher education to provide professional support for students. Building on existing, curricularly anchored coaching formats at the faculty, reflection conversations will be made scalable in the future via the implementation of a Coachbot. Currently, a decision- and text-based StudiCoachBot is conceptualized and developed to deepen students' self-reflection processes on learning and working strategies in a coaching process (Mai \& Richert 2021). In such a process, concerns and goals are defined (e.g., dealing with exam anxiety, developing learning goals and/or strategies, clarifying team roles) in order to implement interventions based on these. These consist of, on the one hand, a structured coaching conversation that uses open-ended questions to deepen students' self-reflections and, on the other hand, 
materials in the form of summaries, videos, reflection tools such as self-assessment tests, and scaling and visualizations to develop goals.

Interaction with a coachbot cannot replace real-life reflection and feedback conversations between students and instructors, but it offers advantages: In AI-based interactions, the willingness to reveal something about oneself may be higher - especially for sensitive topics - because the systems are perceived by users as unbiased. This can lead to students identifying counseling concerns earlier on their own. In addition, AI-based offerings are a good preparation for having in-depth conversations with instructors, for which students can then formulate concrete concerns.

The coaching processes between StudiCoachBot and students are being researched concurrently as part of a PhD project (Mai \& Richert 2020). The StudiCoachBot is being developed within the framework of projects at the Cologne Cobots Lab and Cologne TraingING Center, is closely docked to the Technology Area, and is to be made available university-wide in the future. A suitable system architecture is currently being selected. A curricular anchoring in modules of the BA program in mechanical engineering - e.g. in preparation for reflection discussions with lecturers - is planned.

\subsection{Serious game worlds of materials: Game-based learning in engineering education}

Serious games combine learning situations from the field of education with games from the entertainment industry. These are games or game-like situations that do not primarily serve the purpose of entertainment, but instead focus on learning new skills and competencies. Learning content and learning tasks are integrated into the game world so that new skills can be taught and trained in a playful way. This type of digital exercise form contributes to students' competence enhancement through motivational drivers such as play instinct, fun, need for recognition, competitive spirit and ambition (Young et. al. 2012).

Worlds of Materials is a point-and-click adventure game for students in various engineering programs and those interested in materials science. The game takes student Nicole Nickel through ten parallel dimensions where she encounters different versions of her materials science professor. A mysterious man in black has been manipulating the professors in each of these worlds, keeping them from their assignments. To solve this, the player must use the knowledge gained from the ten chapters of the Fundamentals lecture series. The game design closely adheres to the curriculum, but repeatedly picks up the content of the previous chapters. The goal is to reach levels three (Apply) and four (Analyze) of Bloom's Taxonomy. In the spirit of Open Education, the game, like the lectures, is made freely available. For students of the various engineering sciences at the TH Köln - University of Applied Sciences, who take the elective subject materials science, there is the possibility to get bonus points for the exam by completing the game. However, this option is irrelevant for the game experience: It was explicitly designed to be played by students from other universities as well as by material science enthusiasts.

The game was developed between 2019 and 2021 by a small team of students and staff of the Cologne Game Lab (CGL). The team received technical support from staff members of the Institute for Materials Application (IWA). Since its release in 2021, the effectiveness of the didactic measure has been investigated in a joint research of the IWA and the CGL. The gamification approach can serve as best practice for similar developments in other subjects with regard to technology and didactics. In addition, the game won the German Computer Game Award for best serious game in April 2021.

\section{Structural anchoring of co-creation processes in the house of excellence in engineering education}

The digital transformation of work and everyday life has an impact on qualification goals, the design of teaching and learning formats, and the support of students inside and outside the TH Köln University of Applied Sciences. With their contributions to teaching, research and program development, the measures presented here explore what it means when universities see themselves as open learning systems in which co-creation processes of all university actors are promoted in order to create a framework for individualized study design, personalized learning on the basis of intelligent systems, and a stronger link between research and teaching.

With the measures and processes presented here for the creation of agile learning environments and innovation spaces for prospective mechanical engineers, the faculty at the TH Köln - University of Applied Sciences has taken on a pioneering role and is actively involved in university development processes based on co-creation. In particular, it benefits from the measures implemented in teaching for cross-context and interdisciplinary learning, in which interdisciplinary structures are built up and hierarchical constellations, for example between lecturers and students, are dismantled for structural reasons. Systemic formats such as peer teaming of lecturers, agreement on common basic curricular 
elements and the development of a common language can significantly promote the networked development of hybrid curricula and the further development of curriculum workshops.

The House of Excellence in Engineering Education (HEEE) (TH Köln 2019) professionalizes and structurally anchors the regular reflection on the implementation of these principles within the framework of study program development processes. It bundles the diverse activities in the area of teaching across all study programs at the faculty, promotes the university-wide networking of actors in teaching and research and enables the transfer of innovative teaching concepts to the university. The foundation of the HEEE is the combined integration of professional, methodical and social competences in the study programs. In coaching and training sessions, students and lecturers can continuously reflect on their team and work processes, formulate lessons learned from project work and develop quality patterns for future tasks. Across the common teaching and learning areas of the faculty lie common research topics, which are worked on within the framework of the Scholarship of Teaching and Learning.

In the next step, more consultation activities will be initiated within the framework of the HEEE and the Technology Area in order to develop further teaching/learning innovations together with lecturers and students. Other planned exchange formats to initiate co-creation processes include a Masters Conference in September 2021, at which master's students from the Mechanical Engineering/Smart Systems program will present current research work, and the Faculty Research Day planned for October 2021.

\section{References}

Mai, V. \& Richert, A. (2020). AI Coaching: Effectiveness factors of the working alliance in the coaching process between coachbot and human coachee - an explorative study. In I. Gómez Chova \& A. López Martínez (Eds.), EDULEARN20 Proceedings (pp. 1239-1248). doi: https://library.iated.org/publications/EDULEARN20 : IATED Academy.

Mai, V. \& Richert, A. (2021). StudiCoachBot an der TH Köln - Reflexionsprozesse KI-basiert begleiten. fnma Magazin - Forum neue Medien in der Lehre Austria (01/2021), pp. 21-23. March 26, 2021, from: https://www.fnma.at/publikationen/magazin.

Richert, A., Mai, V., Mengen, H., Wolf, S. (2019). Mixed-Reality-Games in Engineering Education. In A. Cardoso, M.T. Restivo (Eds.), Proceedings of the 2019 5th Experiment@, International Conference (exp.at'19). Online Experimentation (pp. 365-370). Funchal: Institute of Electrical and Electronics Engineers (IEEE).

Stifterverband für die Deutsche Wissenschaft e.V. (2019a). FutureSkills: Welche Kompetenzen in Deutschland fehlen. Diskussionspapier 1. March 29, 2021, from: https://www.stifterverband.org/medien/future-skills-welche-kompetenzen-in-deutschland-fehlen.

Stifterverband für die Deutsche Wissenschaft e.V. (2019b). FutureSkills: Strategische Potentiale für Hochschulen. Diskussionspapier 3. March 29, 2021, from: https://www.stifterverband.org/ medien/future-skills-strategische-potenziale-fuer-hochschulen.

TH Köln (2019). Organisationsstruktur. House of Excellence. March 29, 2021, from: https://www.thkoeln.de/anlagen-energie-und-maschinensysteme/organisationsstruktur_71325.php.

TH Köln (2020). Curriculum 4.0: Kompetenzerwerb für MaschinenbauingenieurInnen im digitalen Zeitalter. March 29, 2021, from: https:/www.th-koeln.de/anlagen-energie-und maschinensysteme /curriculum-40-an-der-fakultaet-fuer-anlagen-energie--und-maschinensysteme_80248.php.

TH Köln (2020a). Mechanical Engineering (Master's program). March 29, 2021, from: https://www.thkoeln.de/en/academics/mechanical-engineering-masters-program_7778.php.

TH Köln (2021). FacING Digitalization: Innovative and Contemporary Education in Engineering Sciences. March 29, 2021, from: https://www.th-koeln.de/anlagen-energie-und-maschinensysteme/ faceing-digitalization_82140.php.

Varney, P., Mai, V., Richert A. (in press): Mixed-Reality-Game FutureING: Research on effectiveness. In: European Journal of Engineering Education. Special Issue: Online Laboratories in Higher Engineering Education: Solutions, Challenges, and Future Directions from a Pedagogical Perspective.

VDMA (2019). Ingenieurinnen und Ingenieure für Industrie 4.0. Impuls-Studie. München.

Verein Deutscher Ingenieure e.V. (VDI) (2019). Ingenieurausbildung für die digitale Transformation. Zukunft durch Veränderung. VDI-Studie April 2019. March 29, 2021, from: https://www.ftinformatik.de/pdf/FTIV-1901-A-02m-VDI-Studie-Ingenieurausbildung-DigitaleTransformation.pdf.

Young, M. F., Slota, S., Cutter, A. B., Jalette, G., Mullin, G., Lai, B. et al. (2012). Our Princess is in Another Castle. A Review of Trends in Serious Gaming for Education. In: Review of Educational Research 82 (1), pp. 61-89. 